\title{
POROUS CARBONS-DERIVED FROM VEGETAL BIOMASS IN THE SYNTHESIS OF \\ QUINOXALINES. MECHANISTIC INSIGHTS
}

M. Godino-Ojer ${ }^{1,2}$, R. Blazquez-García ${ }^{1}$, I. Matos ${ }^{3, *}$, M. Bernardo ${ }^{3}$, I. M. Fonseca ${ }^{3}$, E. Pérez Mayoral $^{1, *}$

${ }^{1}$ Departamento de Química Inorgánica y Química Técnica, Universidad Nacional de Educación a Distancia, UNED, Paseo Senda del Rey 9, Facultad de Ciencias, 28040-Madrid (Spain)

${ }^{2}$ Facultad de Ciencias Experimentales, Universidad Francisco de Vitoria, UFV, Ctra. PozueloMajadahonda km 1.800, 28223, Pozuelo de Alarcón (Madrid, Spain)

3 LAQV/REQUIMTE, Departamento de Química, Faculdade de Ciências e Tecnologia, Universidade Nova de Lisboa, 2829-516 Caparica (Portugal)

* Corresponding authors:

eperez@ccia.uned.es; Phone (+34) 913989047; Fax (+34) 913986697

ines.matos@fct.unl.pt; Phone (+351) 212948300

\section{Dedication:}

This paper is dedicated to Prof. Ziolek on the occasion of her 70th birthday. "Metal-free catalysts in honor of our own Niobium Queen" 


\section{Abstract}

We report herein for the first-time acid biomass-derived carbons from vegetal biomass, with high developed porosity, prepared through the integrating method comprising pyrolysis and surface phosphonation, able to efficiently catalyze the synthesis of quinoxalines from 1,2diamines and $\alpha$-hydroxi ketones, under aerobic conditions. The obtained results indicate that the type and number of acid sites drive the reaction in terms of conversion and selectivity. Furthermore, our experimental and theoretical observations suggest that the preferred reaction pathway for this transformation, in the presence of the investigated acid carbon catalysts, involves cascade reactions including imination reaction between reactants, successive imineenamine and ceto-enol tautomerisms, heterocyclization followed by dehydration, and aromatization. While the acid sites seem to be a relevant role in each reaction step, the system formed by activated carbon and molecular oxygen could be behind the last oxidative reaction to give quinoxalines.

\section{Keywords}

Porous carbons, Nanocatalysts, Fine chemicals, Quinoxalines, Computational methods

\section{Highlights}

Acid biomass-derived carbons efficiently catalyze the synthesis of quinoxalines

The reaction is mainly controlled by the type and number of acid sites in carbon catalysts

The porosity of the investigated catalysts barely influences the observed reactivity 


\section{Introduction}

The use of biomass plays an important role on the development of renewable and sustainable systems presently known as circular economy. Lignocellulosic biomass can be easily converted into low cost and extraordinary versatile carbon materials with interesting physicochemical properties [1]. In the last decades, biomass has gained attention for energy applications, conversion into chemicals and char production, highlighting the related porous activated carbons (ACs) for adsorption processes [2]. Hedychium gardnerianum is an original plant of Asia (India, between the Himalayas and Nepal), which was introduced in the Portuguese islands of Azores and Madeira for ornamental reasons. It is an invasive plant that propagates preferentially in wetlands, forest and agricultural areas. Its rapid growth leads to formation of vast and dense colonies that suffocate the development of native vegetation, which may lead to the modification of the natural habitat of native animals and possible threats to the integrity of forest ecosystems, and it is necessary its periodic removal. This lignocellulosic material can therefore be considered a suitable raw material to obtain activated carbon with catalytic properties [3].

ACs have been widely investigated presenting a great variety of applications including catalysis [4]. In fact, the unique properties of these materials such as chemical and thermal stability, high surface areas, tunable textural properties and adapted surface chemistry make them almost ideal supports or catalysts to synthetize valuable compounds $[5,6]$. The porous structure can be strictly controlled by varying the synthesis conditions, aspect of supreme importance in liquid phase reactions in which diffusional limitations can exist. Biomass-derived carbon surface can be also functionalized in only one-step during the preparation process of the carbon or after that by using post-synthesis strategies, if specific functional groups do not tolerate the carbonization temperature. Particularly, biomass-derived carbons functionalized with hydrophilic groups have been reported in several organic transformations such as esterification/transesterification reactions involved in biodiesel production, etherification, 
acetylation, alkylation, dehydration, rearrangements, biomass transformations, among others [7]. However, to date there are no reports involving these kinds of carbon materials in catalyzing cascade reactions for the synthesis of biologically relevant heterocyclic systems [8][9]. In this context, the goal of this paper is focused onto the one-pot synthesis and characterization of phosphorous functionalized biomass-derived carbons, through the integrating method of pyrolysis and surface phosphonation, efficiently catalyzing the synthesis of quinoxalines. Quinoxaline is an important heterocyclic motif rarely in nature but showing a wide variety of biomedical applications [10]. The most investigated synthetic approaches to prepare quinoxalines consist of the reaction between 1,2-diamines and 1,2-dicarbonyl components, $\alpha$ halo ketones and $\alpha$-hydroxi ketones. Among the catalysts reported for the synthesis of quinoxalines from $\alpha$-hydroxi ketones are iron exchanged molybdophosphoric acid [11], silicasupported sulfuric acid [12] and perchloric acid[13], silica gel [14], zeolites [15], metal-organic frameworks, particularly CuBDC [16], and more sophisticated carbon catalysts such as Ru/C [17] and carbon nanotube-gold nanohybrid [18], among others. In this context, we propose a new family of eco-friendly porous carbons, including both biomass-derived and synthetic carbon materials, with different textural properties and compositions, in which the porous surface is functionalized with different oxygenated functional groups emphasizing on acidic functions such as $-\mathrm{CO}_{2} \mathrm{H},-\mathrm{SO}_{3} \mathrm{H}$ and $-\mathrm{PO}_{3} \mathrm{H}_{2}$, tested in the formation of quinoxaline 1 from $o$-phenylendiamine $\mathbf{2}$ and benzoin $\mathbf{3}$ under aerobic conditions. It is based on our previous studies concerning acid metal-free carbons as highly efficient and environmental catalysts involved in cascade reactions for the synthesis of interesting heterocyclic systems, particularly quinolines and related compounds $[19,20]$. We seek to study the effect of the sample porosity and acidity in the synthesis of quinoxaline $\mathbf{1}$, also considering the biomass valorization for the production of porous carbons highly actives. Additionally, mechanistic insights are also envisioned as function of our experimental and theoretical observations.

\section{Experimental}




\subsection{Preparation of the catalysts}

Three carbon series with different porous structure were prepared: (1) biomass-derived carbons obtained from the chemical activation of the invasive plant Hedychium gardnerianum with $\mathrm{H}_{3} \mathrm{PO}_{4}$. Two impregnation ratios ( $\mathrm{g}$ biomass: $\mathrm{g} \mathrm{H}_{3} \mathrm{PO}_{4}$ ) were used, $1: 1$ and $1: 3$; (2) xerogel mesoporous carbons prepared by resorcinol-formaldehyde polymerization. Modification of the pure carbon surface was carried out by using concentrated $\mathrm{HNO}_{3}$ or $\mathrm{HNO}_{3}$ and $\mathrm{H}_{2} \mathrm{SO}_{4}$ treatments as reported by Matos et al. [21]; and (3) ordered mesoporous carbon according to the experimental protocol reported by Zhao group [22-24]. This method consists of the organicorganic self-assembly approach, using a soft template as a structure-directing agent. First a low molecular weight polymer, RESOL, from polymerized phenol and formaldehyde is prepared to be used as carbon precursor. Subsequently, the pure carbon was submitted to acid treatment with concentrated $\mathrm{HNO}_{3}$.

Carbon materials was labelled as follow: (1) biomass-derived carbons as RCB1 and RCB2 for impregnation ratios of $1: 1$ and $1: 3$, respectively; (2) xerogel as $X$ followed by $N(X N)$ when $X$ treated with $\mathrm{HNO}_{3}$ and $\mathrm{S}$ when $\mathrm{XN}$ was treated with $\mathrm{H}_{2} \mathrm{SO}_{4}(\mathrm{XNS})$; (3) ordered pure mesoporous carbon as $\mathrm{CZ}$ followed by $\mathrm{N}(\mathrm{CZN})$ when $\mathrm{CZ}$ treated with $\mathrm{HNO}_{3}$. In this case, treatment of $\mathrm{CZN}$ with $\mathrm{H}_{2} \mathrm{SO}_{4}$ was not achieved because the porous carbon is destroyed.

\subsubsection{Synthesis of RCB1 and RCB2}

The biomass-derived ACs were prepared by using the stalks from the Hedychium gardnerianum plant collected at São Miguel Island, Azores. The stalks were washed thoroughly with water and then oven dried at $100{ }^{\circ} \mathrm{C}$ for several hours. Afterwards, the dried stalks were mill grounded to obtain particles with around $10 \mathrm{~mm}$ long $\times 2 \mathrm{~mm}$ wide. The biomass particles were then impregnated with $\mathrm{H}_{3} \mathrm{PO}_{4}(85 \% \mathrm{w} / \mathrm{w})$ at two different impregnation ratios, defined as the mass ratio of biomass to activating agent, 1:1 (RCB1) and 1:3 (RCB2). Basically, the biomass particles were immersed into acidic aqueous solutions with the known mass of activating agent and kept stirring at $50{ }^{\circ} \mathrm{C}$ for $5 \mathrm{~h}$. After impregnation, the mixtures were oven dried for $1-2$ days at $70{ }^{\circ} \mathrm{C}$ 
to remove water. The impregnated samples were subsequently carbonized in a quartz reactor placed in an electric tube furnace at vertical configuration. The samples were heated to $500{ }^{\circ} \mathrm{C}$, at $5{ }^{\circ} \mathrm{C} / \mathrm{min}$, and kept for $2 \mathrm{~h}$ under a $\mathrm{N}_{2}$ flow of $150 \mathrm{~cm}^{3} / \mathrm{min}$. After cooling under $\mathrm{N}_{2}$ flow, the samples were Soxhlet washed with deionized water up to constant $\mathrm{pH}$ value $\mathrm{pH}$ of deionized water). The washed samples were oven dried at $105^{\circ} \mathrm{C}$ overnight.

\subsubsection{Synthesis of xerogel carbons, $X$}

The xerogel carbon samples were prepared according to Lin and Ritter [25] by sol-gel technique. The method includes the preparation of a solution containing $5 \%(w / v)$ solids with a resorcinol/formaldehyde mol ratio of 1:2 and a resorcinol/sodium carbonate mol ratio of 50:1. The solution $\mathrm{pH}$ was adjusted with diluted $\mathrm{HNO}_{3}$ until 6.2. Then, the solution was placed in an oven for 7 days at $85{ }^{\circ} \mathrm{C}$, the resulting gel was washed with acetone and dried at $65{ }^{\circ} \mathrm{C}$. Subsequently, the sample was subjected to a thermal treatment under a of $100 \mathrm{~cm}^{3} / \mathrm{min} \mathrm{N}_{2}$ flow using a heating rate of $0.5^{\circ} \mathrm{C} / \mathrm{min}$, first for $5 \mathrm{~h}$ at $110{ }^{\circ} \mathrm{C}$ and then at $800{ }^{\circ} \mathrm{C}$ for $3 \mathrm{~h}$. The obtained carbon was labelled carbon X.

The xerogel carbon $(X)$ was oxidized by treatment with a nitric acid solution $(13 \mathrm{M})$ for $6 \mathrm{~h}(1$ $\mathrm{g} / 20 \mathrm{~cm}^{3}$ ) at $90{ }^{\circ} \mathrm{C}$, then washed with deionized water in Soxhlet until constant $\mathrm{pH}$ and dried in oven at $110^{\circ} \mathrm{C}$ resulting in carbon $\mathrm{XN}$.

The oxidized carbon (XN) was heated at $150{ }^{\circ} \mathrm{C}$ with concentrated sulfuric acid solution $(1 \mathrm{~g}$ carbon/20 $\mathrm{cm}^{3}$ sulfuric acid solution) for $13 \mathrm{~h}$ under $\mathrm{N}_{2}$ atmosphere, washed with deionized water in Soxhlet until pH 7 and then dried in oven at $110^{\circ} \mathrm{C}$ (carbon XNS).

\subsubsection{Synthesis of ordered mesoporous carbons, $\mathrm{CZ}$}

Phenol ( $8 \mathrm{~g}$ ) was dissolved in a $20 \% \mathrm{NaOH}$ solution $(0.371 \mathrm{~g})$ and after formaldehyde ( $37 \mathrm{wt} \%$, $14.5 \mathrm{~g}$ ) was added dropwise. The mixture was kept at $75^{\circ} \mathrm{C}$ for $1.5 \mathrm{~h}$ with stirring. The solution was neutralized with $1 \mathrm{M} \mathrm{HCl}$ and the water present was removed by vacuum distillation at temperature below $50{ }^{\circ} \mathrm{C}$. The product was then dissolved in ethanol in order to obtain $20 \mathrm{wt} \%$ solution of RESOL. This solution was filtered to remove some solid $\mathrm{NaCl}$, thus obtaining the final 
RESOL solution. After the RESOL was prepared, the mesoporous polymer was synthesized. Pluronic F-127 (4.002 g) was dissolved in ethanol (40 g), and the ethanol RESOL solution (4.030 g) was added dropwise to the F-127 solution. The resulting mixture was transferred to dishes and allowed to dry at room temperature overnight. The resulting membrane was heated at 100 ${ }^{\circ} \mathrm{C}$ for $24 \mathrm{~h}$ in an oven. The carbonization of the mesoporous polymer was carried out at a heating rate of $1{ }^{\circ} \mathrm{C} / \mathrm{min}$ and held for $2 \mathrm{~h}$ at $350^{\circ} \mathrm{C}$ and $500^{\circ} \mathrm{C}$ and finally for $5 \mathrm{~h}$ at $750^{\circ} \mathrm{C}$, under $\mathrm{N}_{2}$ flow of $100 \mathrm{~cm}^{3} / \mathrm{min}$, resulting in the ordered mesoporous carbon $\mathrm{CZ}$. CZ surface was oxidized with $\mathrm{HNO}_{3}$ with a $13 \mathrm{M}$ solution, at $90{ }^{\circ} \mathrm{C}$ for $6 \mathrm{~h}\left(1 \mathrm{~g} / 20 \mathrm{~cm}^{3}\right)$. The materials were then washed with deionized water in Soxhlet apparatus until pH 7 and oven dried at $110^{\circ} \mathrm{C}$ (carbon CZN).

\subsection{Characterization of the catalysts}

Textural characterization was performed by $\mathrm{N}_{2}$ adsorption at $-196{ }^{\circ} \mathrm{C}$ on an ASAP 2010 V1.01 B Micromeritics equipment. Elemental analysis of the carbon samples was carried out in a CHNS Analyser (Thermo Finnigan-CE Instruments, model Flash EA 1112 CHNS series). The $\mathrm{pH}$ at the point of zero charge $\left(\mathrm{pH}_{\mathrm{pzc}}\right)$ was determined by reverse mass titration following the method proposed by Noh and Schwarz [26]. X-ray photoelectron spectroscopy measurements were done with an Axis Supra by Kratos Analytical using monochromated Al Ka radiation. With an Xray power of $225 \mathrm{~W}$, the survey was recorded at a pass energy of $160 \mathrm{eV}$ and served for elemental quantification. S $2 p$ and $P 2 p$ detail spectra were recorded at $20 \mathrm{eV}$, whereas $\mathrm{C} 1 \mathrm{~s}$ at $5 \mathrm{eV}$. Data analysis was done with CasaXPS. Fourier transform infrared (FTIR) spectra was obtained over the range $400-4000 \mathrm{~cm}^{-1}$ using a Cary 630 FTIR spectrometer equipped with a diamond attenuated total reflectance (ATR) of Agilent Technologies, with a thermoelectrically cooled dTGS detector and $\mathrm{KBr}$ standard beam splitter. All the spectra were recorded via ATR method with a resolution of $1 \mathrm{~cm}^{-1}$.

\subsection{Catalytic performance}

Briefly, a mixture of $o$-phenylendiamine $2(1 \mathrm{mmol})$ and benzoin $3(1 \mathrm{mmol})$, in toluene $(5 \mathrm{~mL})$, in a three-necked vessel, equipped with thermometer, was placed on a multiexperiment work 
station StarFish (Radley's Discovery Technologies IUK). When the temperature reaches $100{ }^{\circ} \mathrm{C}$, the catalyst was added $(25 \mathrm{mg}$ ) and the reaction mixture was stirred during $240 \mathrm{~min}$. The samples were periodically taken at 15, 30, 60, 120, 180 and $240 \mathrm{~min}$ and the catalyst was filtered off and the solvent evaporated in vacuo. The catalysts were milled and sieved to $\mathrm{dp}<0.25 \mathrm{~mm}$, in order to avoid mass transfer limitations. Before use, carbon catalysts were activated at $60^{\circ} \mathrm{C}$ overnight.

The reactions were followed by TLC chromatography performed on DC-Aulofolien/Kieselgel 60 F245 (Merk) using mixtures of $\mathrm{CH}_{2} \mathrm{Cl}_{2} / \mathrm{EtOH}$ 98:2 as eluent. The reaction products were characterized by ${ }^{1} \mathrm{H}$ NMR spectroscopy. NMR spectra were recorded by using a Bruker AVANCE DPX-300 spectrometer (300 MHz for ${ }^{1} \mathrm{H}$ ). ${ }^{1} \mathrm{H}$ chemical shifts in $\left[\mathrm{D}_{6}\right] \mathrm{DMSO}$ or $\mathrm{CDCl}_{3}$ are referenced to internal tetramethylsilane. Experiments of Ultra Performance Liquid Cromatography-Mass Spectrometry (UPLC-MS) was achieved using the cromatograph UPLC Waters Acquity I Class coupled to mass spectrometer maXis II, Bruker (MS-ESI electrospray ionization, positive mode) Characterization data of quinoxalines 1, $\mathbf{7}$ and $\mathbf{8}$ are in good agreement with those previously reported using other catalytic systems [27].

\subsection{Computational methods}

All calculations were performed with the Gaussian 09 software package [28]. All geometries were optimized using $B 3 L Y P / 6-31+G(d, p)$. The stationary points were characterized by means of harmonic vibrational frequency analysis. Thus, the transition structures were confirmed to be first-order saddle points. The imaginary frequency was inspected in each to ensure it represented the desired reaction coordinate. For key transition states the intrinsic reaction coordinate (IRC) was followed to ensure it connects the reactants and products.

Based on previous studies [20], we select the most reduced models simulating the active centers of the catalysts under study (Chart 1 ). 
<smiles>O=C(O)c1ccccc1</smiles>

(a)<smiles>O=S(=O)(O)c1ccccc1</smiles>

(b)<smiles>O=P(O)(O)c1ccccc1</smiles>

(c)

Chart 1. Selected reduced models simulating the acid active centers in the catalysts under study.

(a) Carbons treated with $\mathrm{HNO}_{3}$ (XN and CZN), (b) xerogel treated with $\mathrm{HNO}_{3}$ but also with $\mathrm{H}_{2} \mathrm{SO}_{4}$ (XNS) and (c) biomass-derived carbons activated with $\mathrm{H}_{3} \mathrm{PO}_{4}$ (RCB1 and RCB2).

\section{Results and discussion}

\subsection{Synthesis and characterization of the catalyst}

We prepared three different series of acid metal-free porous carbons. Firstly, we synthetized two biomass-derived carbons by activation of invasive vegetal specie with different amounts of $\mathrm{H}_{3} \mathrm{PO}_{4}$. Furthermore, for comparison purposes we prepared two different pure carbonaceous materials, a mesoporous xerogel by resorcinol-formaldehyde polymerization and an ordered mesoporous carbon, which were subsequently modified by acid treatments to obtain carbons with different textures and acid character. The carbons were characterized to determine the features of the catalysts.

The textural characteristics of the biomass derived carbons presented in Table 1 allow concluding that the chemical activation of the Hedychium gardnerianum biomass with $\mathrm{H}_{3} \mathrm{PO}_{4}$ is a suitable methodology to prepare ACs with highly developed porosity. It was possible to obtain a carbon with a BET area of $2197 \mathrm{~m}^{2} \mathrm{~g}^{-1}$ and a pore volume of $1.39 \mathrm{~cm}^{3} \mathrm{~g}^{-1}$ (RCB2) which is comparable or even higher than many commercial carbons. RCB1 and RCB2 carbons present isotherms of type I (b) which means that these materials have pore size distributions over a wide range including wider micropores. Also, their isotherms present large $\mathrm{H} 4$ hysteresis, indicating that a large mesopore volume is also present [29]. It is also possible to observe that the increase in $\mathrm{H}_{3} \mathrm{PO}_{4}$ amount in the preparation procedure favored the development of microporosity 
increasing around 2.5 times the microporous volume (from 0.23 in RCB1 to $0.59 \mathrm{~cm}^{3} \mathrm{~g}^{-1}$ in RCB2) while the mesoporosity only increase 1.3 times (Table 1 ).

Pore size distribution of the biomass derived carbons was obtained from the Non-Local Density Functional Theory (NLDFT) equilibrium model for carbon slit-shaped pores (Figure 1). Based on these calculations, these carbon samples have primarily micropores with a pore width around 1-1.8 nm. It can also be observed that RCB2 sample presents a higher content of mesopores with 2.3 - $4 \mathrm{~nm}$ width, but the content in mesopores with widths above $5 \mathrm{~nm}$ is very similar for both carbon samples.

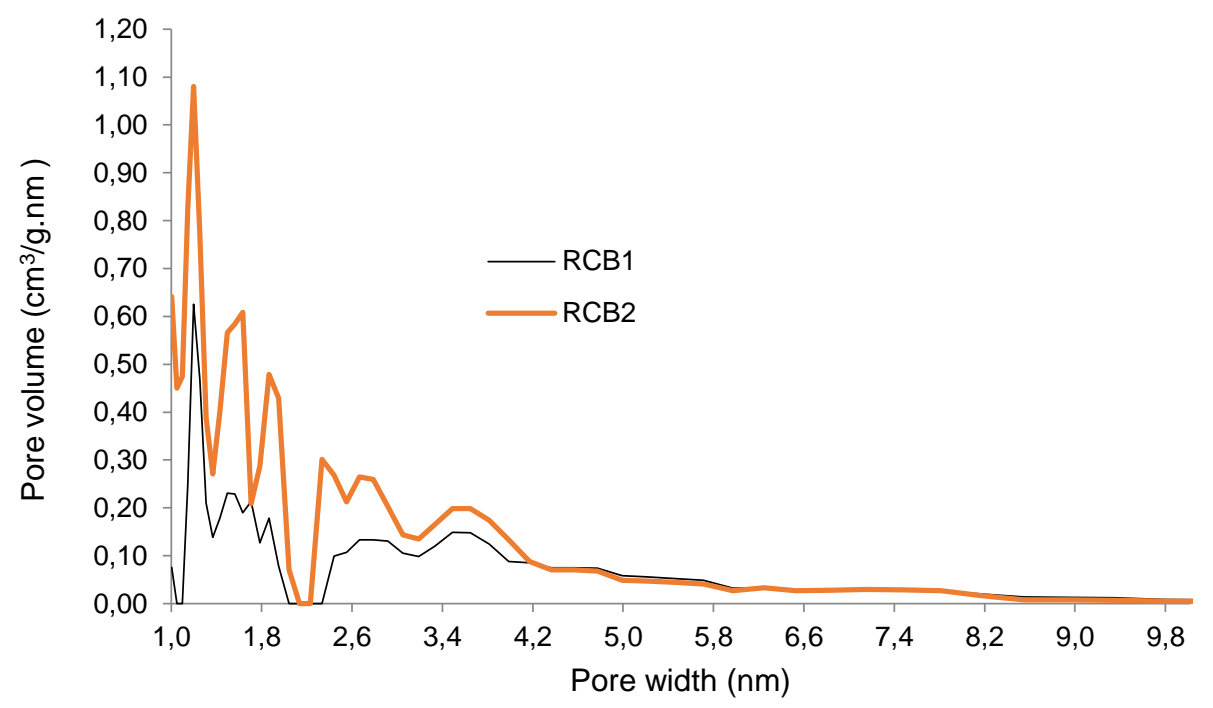

Figure 1. NLDFT pore size distribution of the biomass derived carbons.

Table 1. Textural parameters obtained from $\mathrm{N}_{2}$ adsorption-desorption isotherms of carbon samples.

\begin{tabular}{cccccc}
\hline \multirow{2}{*}{ Catalyst } & $\mathrm{S}_{\mathrm{BET}}\left(\mathrm{m}^{2} \mathrm{~g}^{-1}\right)$ & $\mathrm{V}_{\text {micro }}\left(\mathrm{cm}^{3} \mathrm{~g}^{-1}\right)$ & $\mathrm{V}_{\text {meso }}\left(\mathrm{cm}^{3} \mathrm{~g}^{-1}\right)$ & $\mathrm{V}_{\mathrm{T}}\left(\mathrm{cm}^{3} \mathrm{~g}^{-1}\right)$ & $\mathrm{Dp}_{\mathrm{BJH}}(\mathrm{nm})$ \\
\cline { 2 - 6 } & B.E.T. & t-plot method & BJH method & Gurvitsh & BJH method \\
\hline X & 552 & 0.16 & 0.11 & 0.28 & 1.7 \\
XN & 347 & 0.11 & 0.45 & 1.14 & 1.53 \\
XNS & 448 & 0.15 & 0.57 & 1.27 & 1.71 \\
CZ & 749 & 0.15 & 0.29 & 0.41 & 3.19 \\
CZN & 576 & 0.10 & 0.22 & 0.37 & 3.40 \\
\hline
\end{tabular}




\begin{tabular}{llllll}
\hline RCB1 & 1076 & 0.23 & 0.58 & 0.81 & 1.94 \\
RCB2 & 2197 & 0.59 & 0.77 & 1.39 & 1.94
\end{tabular}

SBET - apparent surface area; B.E.T. - Brunauer, Emmet, and Teller method; $V_{\text {micro }}$ - micropore volume; $\mathrm{V}_{\text {meso }}$ - mesopore volume; $\mathrm{V}_{T}$ - total pore volume; $\mathrm{Dp}$ - pore diameter; $\mathrm{BJH}$ - Barrett, Joyner, and Halenda method.

The synthesized carbon CZ presents a BET area of $749 \mathrm{~m}^{2} \mathrm{~g}^{-1}$, value comparable to those of the literature [30], and a typical isotherm (type IV) and hysteresis ( $\mathrm{H} 2$ ) for ordered mesoporous material. However, these carbons also present microporosity, probably developed in the walls of larger pores. The XN sample predominantly shows meso- and macroporosity presenting smaller $\mathrm{S}_{\mathrm{BET}}$.

The surface characteristics of the samples were also analysed by elemental analysis, XPS and $\mathrm{pH}_{\mathrm{PzC}}$ (Table 2 and 3). The elemental analysis of the biomass derived carbons revealed the high oxygen content of the samples, these results combined with the low values of $\mathrm{pH}_{\mathrm{pzc}}$ of the RCB1 and RCB2 suggests that the activation with phosphoric acid alone resulted in not only high porosity, but also functionalization of the carbon surface. This effect is also probably due to the presence of phosphorous groups at the surface of the catalysts, which was confirmed by XPS studies.

The oxidation of the carbons surface resulted in the increase of oxygen content and consequent decrease in $\mathrm{pH}_{\mathrm{pzc}}$ attributed to the introduction of acid functional groups. The treatment of $\mathrm{XN}$ with sulfuric acid resulted in a decrease of oxygen content but the acidity of the sample XS was increased, revealing the successful introduction of strong acid sulfonic groups in the sample.

Table 2. Surface chemistry characterization. Elemental composition (expressed on wt\%) determined by elemental analysis (E.A).and $\mathrm{pH}_{\mathrm{PZC}}$ of the carbon materials.

\begin{tabular}{c|ccccc|c}
\hline Sample & $\mathbf{C}$ & $\mathbf{H}$ & $\mathbf{N}$ & $\mathbf{S}$ & $\mathbf{0}$ & $\mathbf{p H}$ PZC \\
\hline $\mathbf{X}$ & 89.9 & 0.9 & 0.0 & 0.0 & 9.2 & 9.7 \\
$\mathbf{X N}$ & 73.9 & 1.3 & 0.4 & 0.0 & 27.8 & 3.3 \\
\hline
\end{tabular}




\begin{tabular}{c|ccccc|c}
\hline XNS & 84.2 & 1.3 & 0.03 & 0.4 & 17.5 & 2.8 \\
CZ & 91.9 & 0.7 & 0.0 & 0.0 & 7.4 & 9.0 \\
CZN & 73.3 & 1.2 & 0.7 & 0.0 & 24.8 & 3.2 \\
RCB1 & 62.3 & 2.3 & 0.5 & 0.0 & 35.0 & 2.4 \\
RCB2 & 89.8 & 1.0 & 0.5 & 0.0 & 8.7 & 3.0 \\
\hline
\end{tabular}

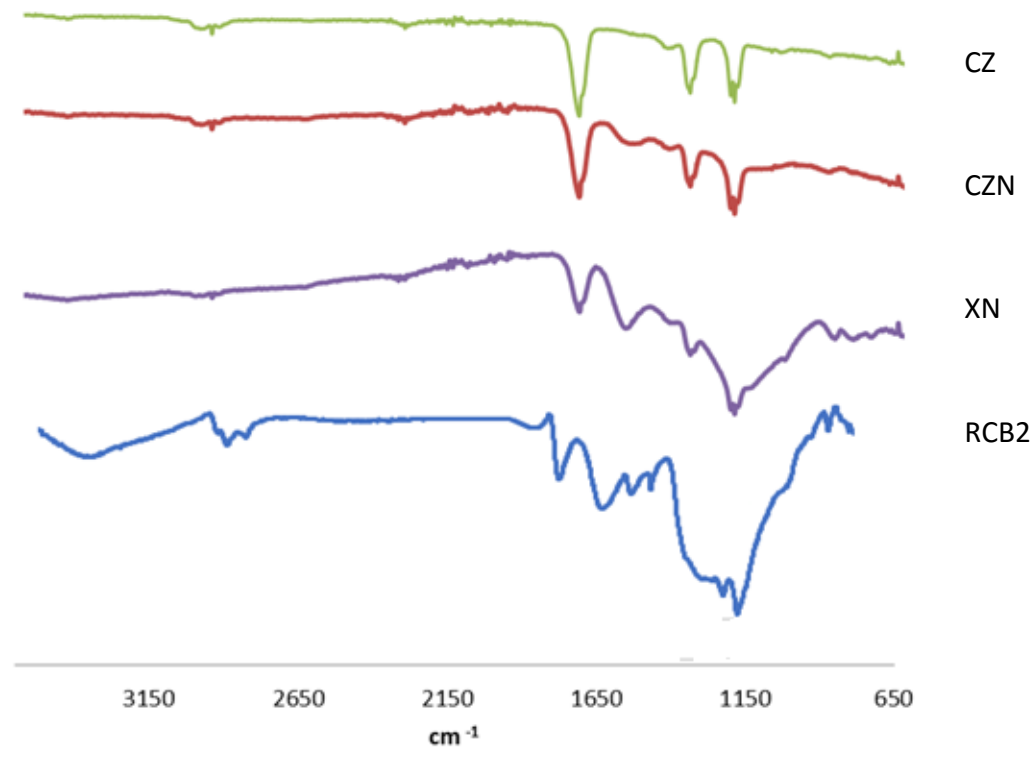

Figure 2. FTIR spectra of the carbon catalysts $C Z, C Z N, X N$ and RCB2.

The FTIR spectra of the different samples show some differences in the carbon materials (Figure 2). The $C Z$ and $C Z N$ carbons present spectra with better defined bands probably due to the ordered nature of the material. All the carbons have bands in the same characteristic regions for carbon type materials [31]. The absorption bands around $2900 \mathrm{~cm}^{-1}$ are assigned to $\mathrm{C}-\mathrm{H}$ stretching in aliphatic series, while the band at approximately $1730 \mathrm{~cm}^{-1}$ is usually assigned to $\mathrm{C}=\mathrm{O}$ stretching vibrations of ketones, aldehydes, lactones or carboxyl groups. Around $1580 \mathrm{~cm}^{-1}$ is the band associated with the $\mathrm{C}-\mathrm{C}$ vibrations in aromatic rings and the broad band between $1100-1200 \mathrm{~cm}^{-1}$ is common in oxidized carbons and normally assigned to the $\mathrm{C}-\mathrm{O}$ stretching in acids, alcohols, phenols, ethers and/or esters groups. However, the CZN sample presents two distinct bands at 1370 and $1220 \mathrm{~cm}^{-1}$ also assigned to oxidized forms. In the same context, the 
biomass derived carbon presents an even broader band with a shoulder, which has also been reported as characteristic of carbons obtained using phosphoric acid and can be assigned to the stretching mode of hydrogen-bonded $\mathrm{P}=\mathrm{O}$, to $\mathrm{O}-\mathrm{C}$ stretching vibrations in $\mathrm{P}-\mathrm{O}-\mathrm{C}$ (aromatic) linkage and to $\mathrm{P}=\mathrm{OOH}[32]$.

Table 3. Surface chemistry characterization. Elemental composition (expressed on atomic \%) of the carbon materials determined by XPS.

\begin{tabular}{|c|c|c|c|c|c|c|}
\hline Sample & $\mathrm{C} 1 \mathrm{~s}^{[\mathrm{a}]}$ & $01 s^{[a]}$ & $S 2 p^{[a]}$ & $P 2 p^{[a]}$ & $O / C^{[b]}$ & $\mathrm{O} / \mathrm{C}^{[\mathrm{c}]}$ \\
\hline XN & 87.7 & 12.2 & 0.0 & 0.0 & 0.14 & 0.28 \\
\hline XNS & 93.5 & 6.4 & 0.2 & 0.0 & 0.07 & 0.16 \\
\hline CZ & 84.0 & 16.0 & 0.0 & 0.0 & 0.14 & 0.06 \\
\hline CZN & 78.4 & 23.6 & 0.0 & 0.0 & 0.23 & 0.25 \\
\hline RCB2 & 88.2 & 9.14 & 0.0 & 2.3 & 0.10 & 0.07 \\
\hline
\end{tabular}

[a] Determined by XPS; [b] atomic ratio determined by XPS; [c] atomic ratio determined by E. A.

The XPS study of the biomass derived sample RCB2 was particularly important to determine the presence of phosphorous in the resulting carbon matrix. The XPS P2p peak was located at binding energy (BE) around $133 \mathrm{eV}$ and could be fitted to assign the contribution of two peaks one at $132.8 \mathrm{eV}$ and another at $133.6 \mathrm{eV}$. These contributions to the P2p zone can be described as $\mathrm{P}$ groups directly bonded to a carbon site $\left(\mathrm{CPO}_{3}\right.$ or $\mathrm{C}_{2} \mathrm{PO}_{2}$ group), or with a bridge $\mathrm{O}$ atom $\left(\mathrm{COPO}_{3}\right.$ or $(\mathrm{CO})_{3} \mathrm{PO}$ groups $)[33,34]$.

Sample XNS is the only one where the sulphur element is observed, the BE values suggesting an oxidized form of sulphur probably in the form of sulphate or sulfonic groups $\left(-\mathrm{OSO}_{3} \mathrm{H}\right.$ or $\left.-\mathrm{SO}_{3} \mathrm{H}\right)[35]$

The $\mathrm{BE}$ of the $\mathrm{C} 1 \mathrm{~s}$ spectrum characteristic of $\mathrm{ACs}$ are observed in all samples. The fitting of the $\mathrm{C}$ 1s peak of all samples showed a predominant C sp2 component and then a smaller contribution of oxidized forms of carbon, corresponding to alcohol/ ether $\left(-\mathrm{COH},-\mathrm{COC}-, \mathrm{O} \mathrm{C}\left(\mathrm{O}-\mathrm{C}^{*}\right)\right)$, carbonyl $(-\mathrm{C}=\mathrm{O})$, and carboxyl $(\mathrm{COOH})$ functional groups at BEs of $286.3 \mathrm{eV}, 287.8 \mathrm{eV}$ and 288.7 eV respectively [36,37]. 
For XN sample it is observed the predominance of alcohol or esters functional groups, while the biomass derived carbon RCB2 presented a more even contribution of the different functional groups. After oxidation, the sample CZN revealed a sharp increase in surface oxygen content and a stronger contribution of $\mathrm{CO}$.

Sample CZN seems to present a homogeneous distribution of oxygen functional groups since the atomic ratio $\mathrm{O} / \mathrm{C}$ determined by XPS is similar to the one determined by elemental analysis. The contrary trend is observed for the xerogel samples XN and XNS revealing a preferential oxidation and oxygen deposition inside the pores, thus not detectable by XPS.

On the other hand, for the RCB2 sample the atomic ratio O/C determined by XPS is similar to the value obtained for the $\mathrm{O} / \mathrm{C}$ ratio determined by elemental analysis. Since the oxidation of the carbons resulted from the activation procedure, it was possible to obtain a material with a homogeneous distribution of the oxygen surface groups throughout the carbon.

\subsection{Catalytic performance}

The catalysts were tested in the synthesis of quinoxaline $\mathbf{1}$ from o-phenylendiamine $\mathbf{2}$ and benzoin 3 , under aerobic conditions, in toluene, at $100^{\circ} \mathrm{C}$ (Scheme 1$)$.

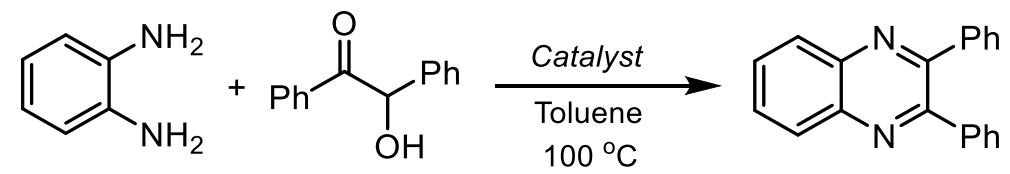

Scheme 1. Synthesis of quinoxaline $\mathbf{1}$ from $\boldsymbol{o}$-phenylendiamine $\mathbf{2}$ and benzoin $\mathbf{3}$, under aerobic conditions, in toluene, at $100{ }^{\circ} \mathrm{C}$, catalyzed by porous carbon materials.

Firstly, we check the catalytic behavior of a pure carbon such as CZ for comparison with the modified sample CZN. Figure 3 depicts the conversion of diamine 2 vs time for both catalysts. As it can be observed, carbon $\mathrm{CZ}$ is active in the selected reaction with high conversion values but diminished selectivity to quinoxaline 1 (Figure 3). 
$\sim \mathrm{CZ} \backsim \mathrm{CZN}$

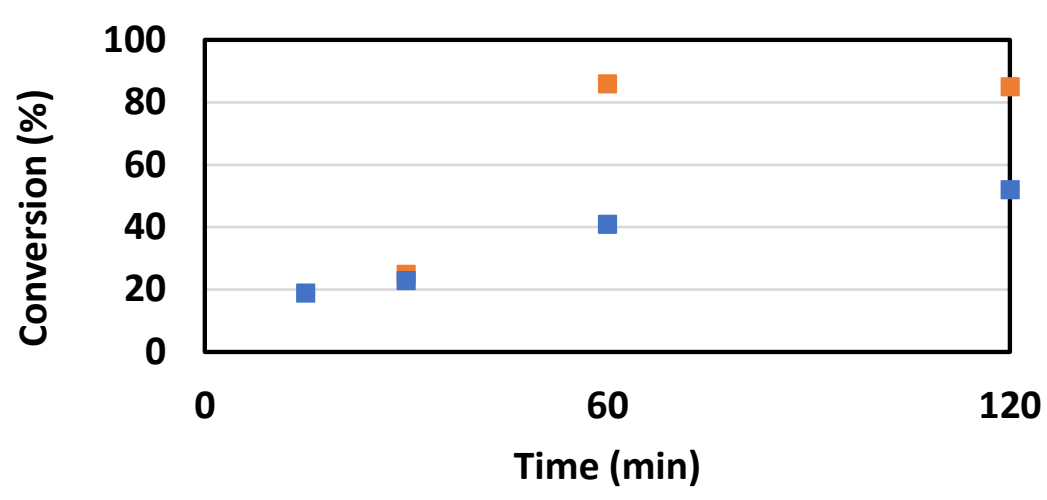

$\mathrm{CZ} \backsim \mathrm{CZN}$

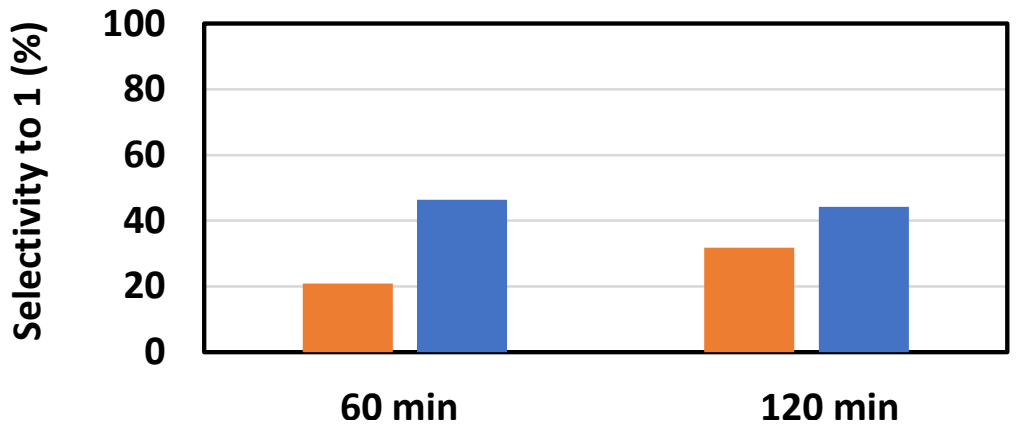

Figure 3. Synthesis of quinoxaline $\mathbf{1}$ from o-phenylendiamine $\mathbf{2}$ and benzoin $\mathbf{3}$, under aerobic conditions, in toluene, at $100^{\circ} \mathrm{C}$, catalyzed by $\mathrm{CZ}$ and CZN catalysts.

The analysis of the ${ }^{1} \mathrm{H}$ NMR spectra of the samples at different reaction times reveals the formation of the corresponding quinoxaline $1(27 \%, 2 \mathrm{~h})$ together with the intermediate 4 (49\%, $2 \mathrm{~h}$ ) as major reaction product, these results in good agreement with previous studies using graphite as catalyst [38]. It was also detected the presence of additional signals in the aromatic region at $\delta=8.2$, overlapping the corresponding signals of aromatic protons in quinoxaline skeleton. The absence of any aliphatic protons strongly suggests the formation of additional intermediate specie whose structure could be assigned to compound 5 (Scheme 2) as also suggested by UPLC-MS experiments. The obtained results suggest that the carbon matrix predominantly catalyzes the conversion of reagents into the intermediate compound 4 . Both samples, CZ and CZN, barely show differences on their textural properties but also in the acid- 
base properties, $\mathrm{CZN}$ showing high acid character ( $\mathrm{pH}_{\mathrm{pZC}} 3.2$ vs 9 for the $\mathrm{CZ}$ sample). Therefore, the observed reactivity is attributed to the presence of acid functions in CZN sample, as expected.

Scheme 2 also summarizes the accepted mechanisms reported for the investigated reaction consisting of the cascade reactions condensation-dehydration-cyclization and aromatization (Scheme 2, Path a) [39] or initial benzoin oxidation followed by double condensation and dehydration to yield 2,3-diphenylquinoxaline 1 (Scheme 2, Path b) [11]. It is noticeable that in our case benzyl $\mathbf{6}$ as oxidation product from benzoin or intermediate compound $\mathbf{7}$ were not detected. Therefore, these results open the doors to consider other alternative reaction pathway for the formation of quinoxaline $\mathbf{1}$ in the presence of acid carbon catalysts probably following the Path c.

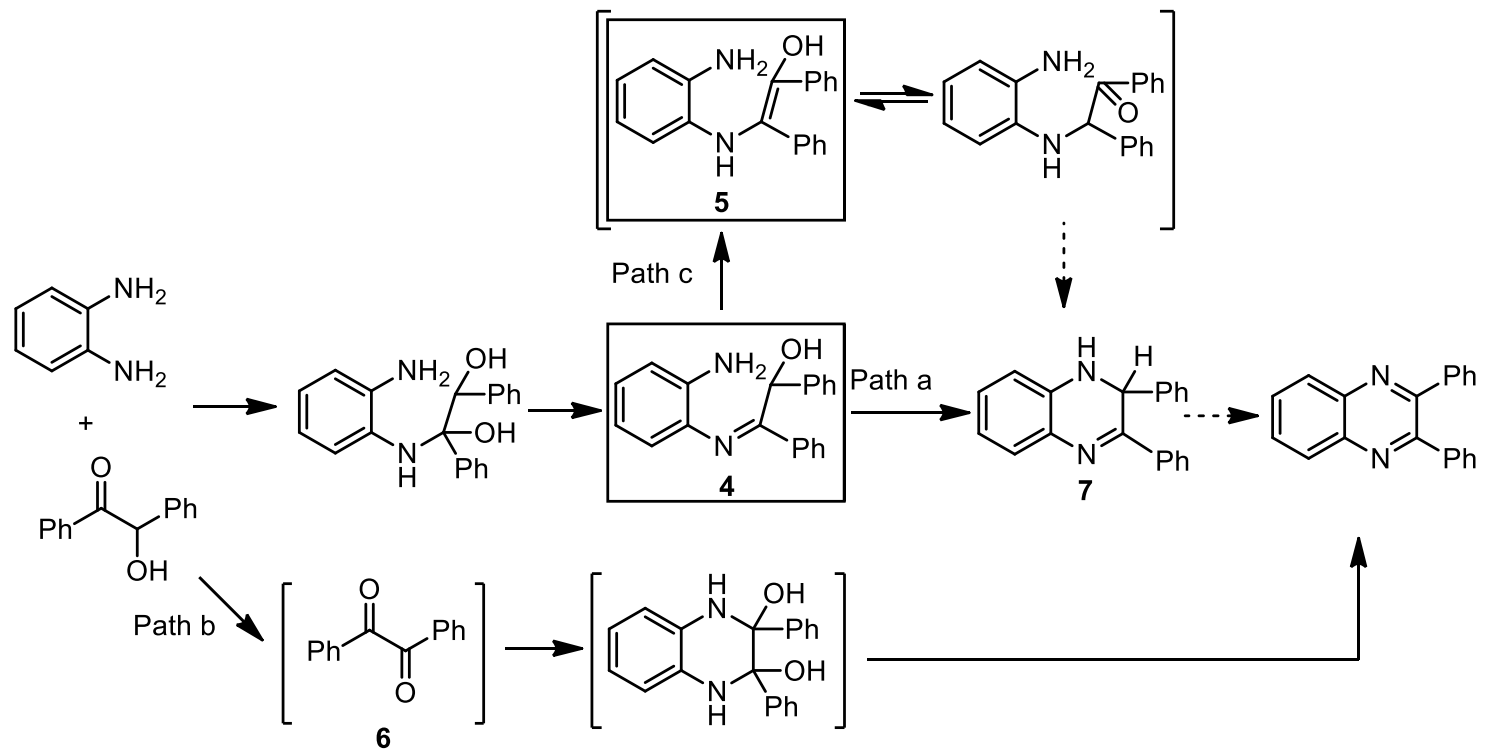

Scheme 2. Reaction mechanisms accepted for the synthesis of quinoxaline $\mathbf{1}$ (Path a and b). Alternative pathway for the synthesis of quinoxaline $\mathbf{1}$ in the presence of acid carbon catalysts (Path c). 
Following our ongoing investigations, we explore the reaction under the same experimental conditions in the presence of porous carbon xerogels (Figure 4). XN catalyst results in the highest conversion values compared to XNS sample although with diminished selectivity to product 1.

In this case it seems that the important feature to selectivity is type and strength of acid sites. The number of acid sites may account for activity, but the type of acid sites determine selectivity. In both cases no evident relation is found between textural properties and catalytic performance. The reaction also occurs at lower temperature $\left(80^{\circ} \mathrm{C}\right)$ giving lower conversion values ( $\mathrm{XN}=61 \% ; 3 \mathrm{~h}$ ) with maintained selectivity, as expected. The non-activated $\mathrm{XN}$ catalyst leads to lower conversion values but surprisingly superior selectivity at all reaction times, this effect attributed to the presence of water on the hydrophilic surface, as briefly commented in mechanistic consideration section.
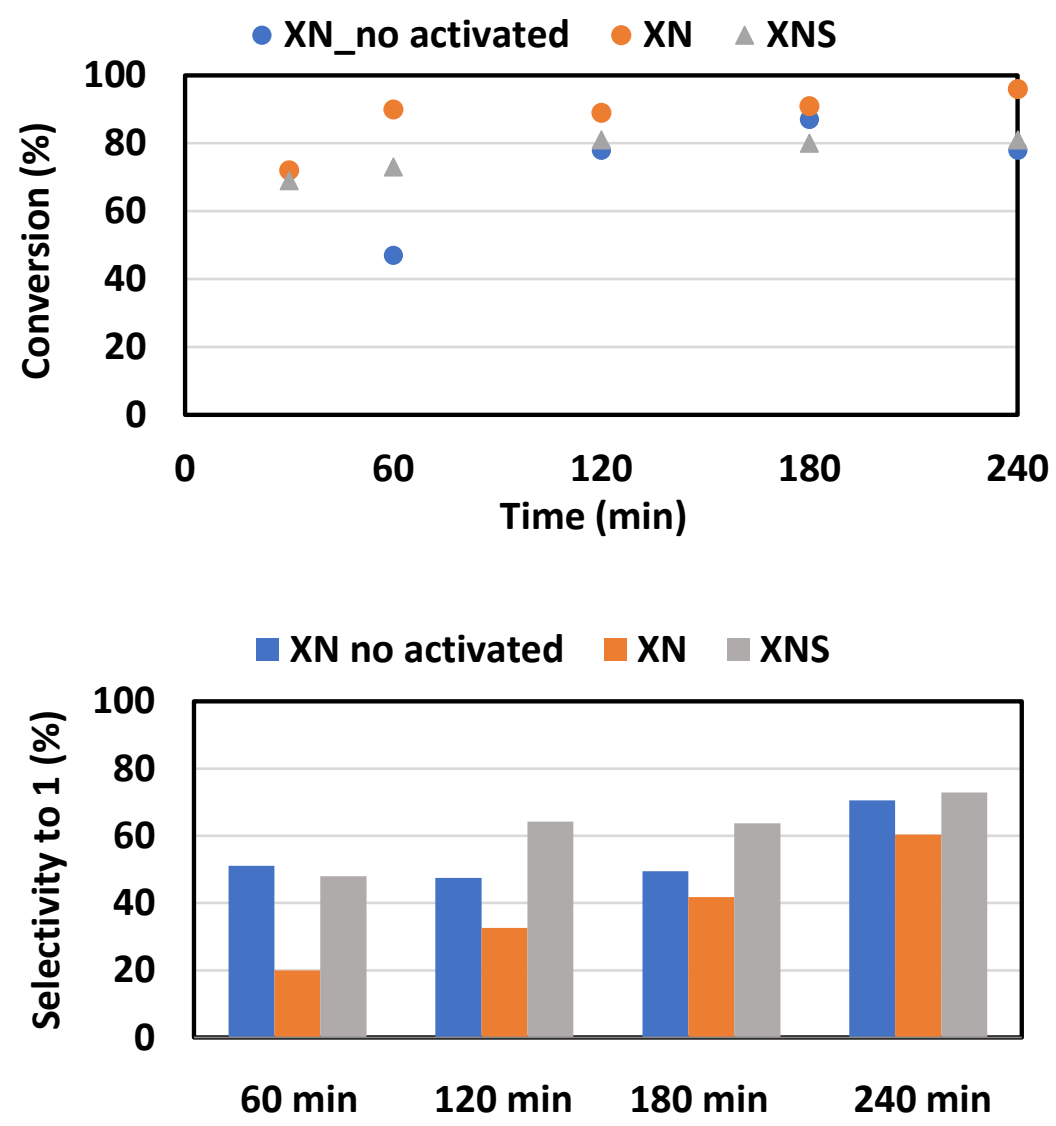

Figure 4. Synthesis of quinoxaline $\mathbf{1}$ from $\boldsymbol{o}$-phenylendiamine $\mathbf{2}$ and benzoin $\mathbf{3}$, under aerobic conditions, in toluene, at $100{ }^{\circ} \mathrm{C}$, catalyzed by xerogels XN and XNS. 
Comparing both $\mathrm{XN}$ and CZN samples it was observed and increase of conversion values for XN but a diminished selectivity to 1 increasing with reaction time. Given the almost equal acidity of both samples, the higher selectivity for CZN could be because of the ordered channel structure.

Finally, we check the biomass-derived carbons in the reaction without almost differences on their catalytic behavior in terms of conversion and selectivity (Figure 5).
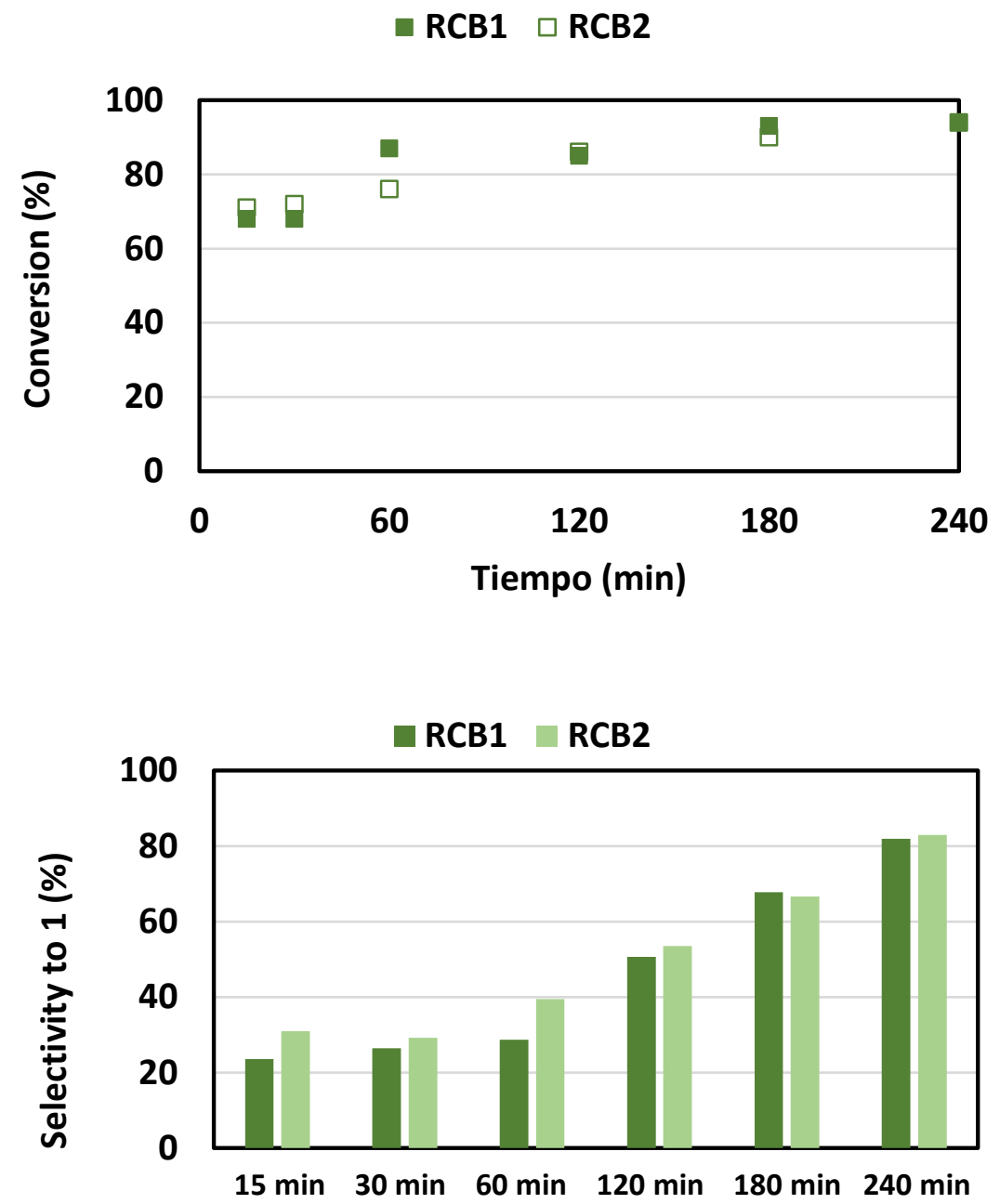

Figure 5. Synthesis of quinoxaline $\mathbf{1}$ from o-phenylendiamine $\mathbf{2}$ and benzoin $\mathbf{3}$, under aerobic conditions, in toluene, at $100{ }^{\circ} \mathrm{C}$, catalyzed by biomass-derived porous carbons.

Given the high microporosity of RCB1 and RCB2 complemented by the presence of mesoporous, high conversion was expected, although it seems in this case the textural parameters were not 
enough to differentiate the catalysts. While XN and RCB1 or RCB2 give similar conversion values, selectivity to 1 was notably increased in the presence of biomass-derived carbons. Similarly, as for XN and XNS, the enhanced selectivity seems to be related with the type and strength of acid sites. Although XN presents higher amount of oxygen acid sites (detected by XPS), the presence of sulfur or phosphor acid groups drives the reaction for the desired product. Therefore, it seems that the reaction selectivity is mainly controlled by the type and strength of acid catalytic centers following the order XNS $>$ RCB2 $>$ XN at shortest reaction times (Figure 6). The lower selectivity for biomass-derived samples regarding to XNS (after 1 and $2 \mathrm{~h}$ ) although increased with the time could be related to the high adsorption of intermediate species (see mechanistic considerations section).

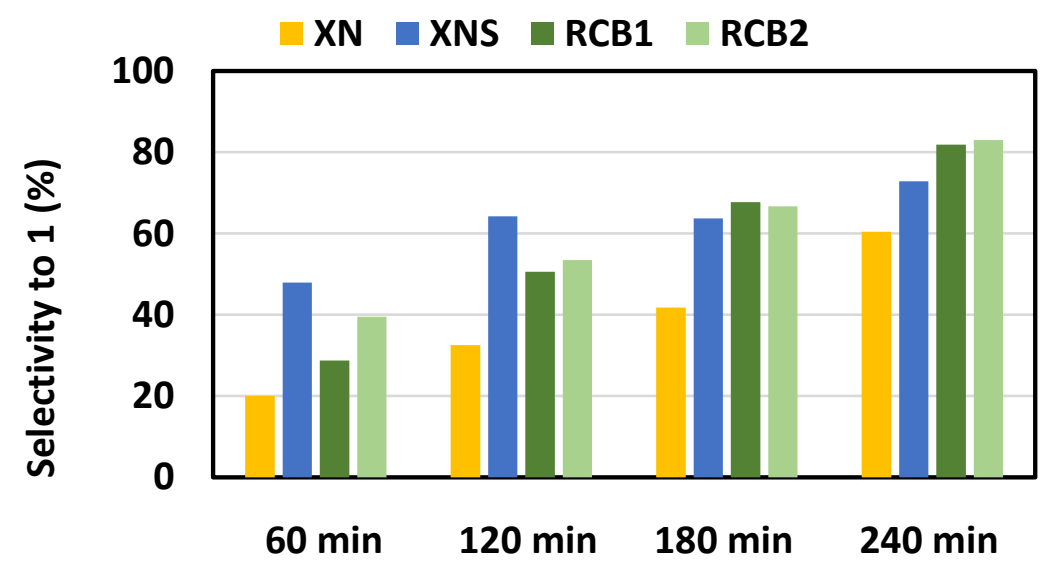

Figure 6. Selectivity to $\mathbf{1}$ for the investigated acid carbon catalysts.

Figure 7 shows the evolution of the reaction catalyzed by RCB2 sample in which it can be observed the formation of quinoxaline $\mathbf{1}$ while both intermediate compounds $\mathbf{4}$ and $\mathbf{5}$ disappearing. Additionally, recycles experiment was carried out by using RCB2 sample observing diminished conversion values of around $10 \%$ for the second and third cycles with maintained selectivity to 1 . 


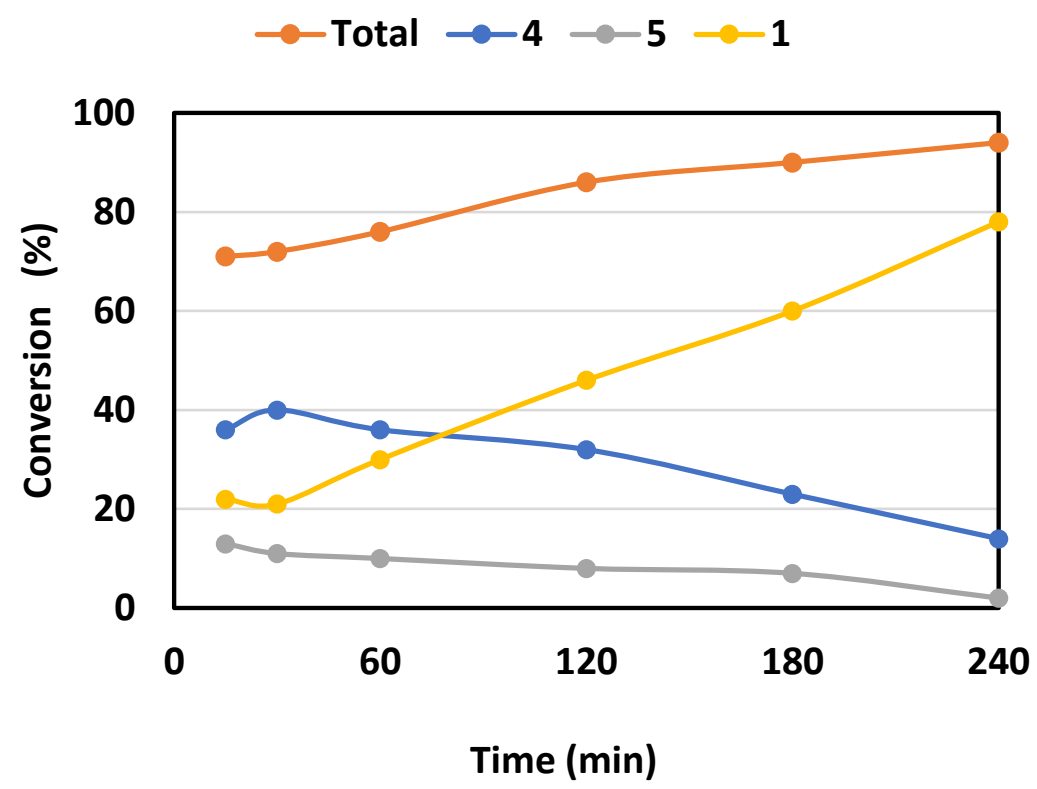

Figure 7. Synthesis of quinoxaline $\mathbf{1}$ from o-phenylendiamine $\mathbf{2}$ and benzoin $\mathbf{3}$, under aerobic conditions, in toluene, at $100^{\circ} \mathrm{C}$, catalyzed by biomass-derived porous carbon RCB2. Evolution of the reaction.

Finally, we study the scope of the methodology by using different $\alpha$-hydroxi ketones and another diamine under the same experimental conditions in the presence of the one of the most efficient catalysts, RCB2 sample (Scheme 3).

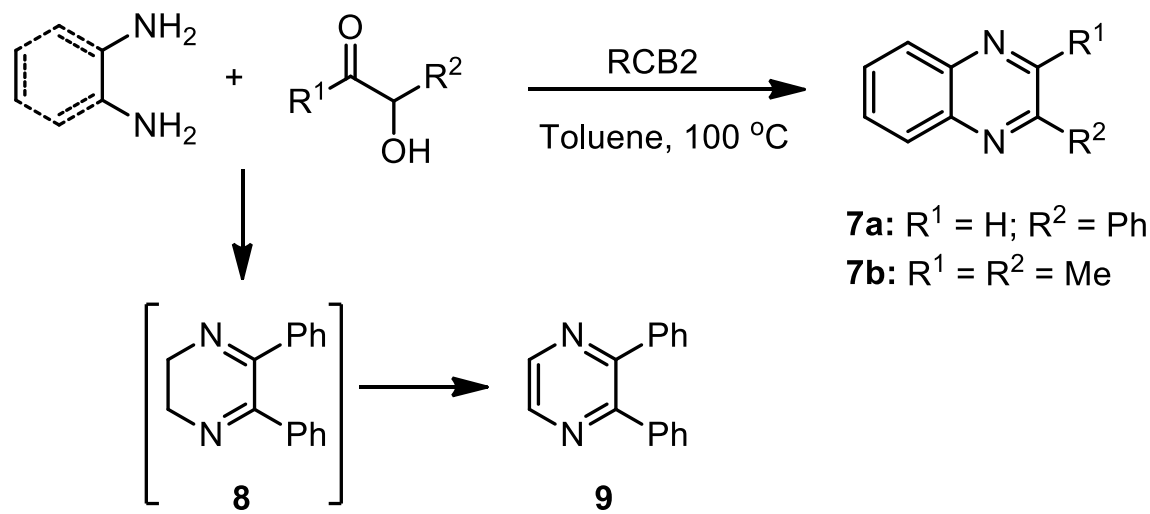

Scheme 3. Synthesis of nitrogen heterocycles catalyzed by biomass-derived carbon RCB2, in toluene at $100{ }^{\circ} \mathrm{C}$. 
Remarkably, quinoxaline $7 a$ was obtained in $71 \%$ with total selectivity in only 30 min of reaction time, while when using acetoin $\left(R^{1}=R^{2}=M e\right)$ it was observed the formation of $7 b$ in $60 \%$ with significant decreased selectivity (60\%) after 4 h. The formation of intermediate compounds $\mathbf{1 2}$ as Z/E isomers in 1:1 ratio was detected which was progressively transformed into quinoxaline 7b. It is noteworthy that in this case total conversion was observed after only 30 min of reaction time providing $49 \%$ of quinoxaline $\mathbf{7 b}$. Additionally, we also prepared the dihydropyrazine 8 starting from ethylendiamine and benzoin $\mathbf{3}$ in 96\% of yield with almost total selectivity (96\%), after only 30 min of reaction time, which by oxidative aromatization gradually lead to pyrazine $9(60 \%, 4 h)$.

In summary, the obtained results are especially relevant because it supposes the easy technological valorization of the biomass into acidic porous carbons able to efficiently catalyze the synthesis of quinoxalines from o-phenylendiamine $\mathbf{2}$ and different $\alpha$-hydroxi ketones, under aerobic conditions.

\subsection{Mechanistic considerations}

Based on our experimental results and considering other alternative reaction mechanism for the transformation of $o$-phenylendiamine $\mathbf{2}$ and benzoin $\mathbf{3}$ into quinoxaline $\mathbf{1}$ catalyzed by acid carbon catalysts, we carried out a succinct theoretical study by analyzing each step as an elementary reaction in gas phase. We select the most reduced models containing exclusively acid functions simulating each series of catalysts (Chart 1 ) but also the simplest $\alpha$-hydroxi ketone for decreasing the computational cost. Obviously, these models do not represent a realistic situation only allowing to analyze the effect of different acid centers in the reaction without any confinement restrictions. It seems reasonable to think that the reaction could follow alternative routes (Paths b or $\mathrm{c}$ ) as shown in scheme 4. Additionally, we firstly investigate the formation of the intermediate compound $\mathbf{1 6}$ from $\mathbf{I} \mathbf{2}$ in absence or in the presence of the catalysts, particularly using the N-model, following the path a, as reported (Scheme 4, Path a). Thus, the computed 
transition structures for this transformation in absence $\left(\mathbf{T S}_{\mathbf{1 2 - 1 6}}\right)$ or using $\mathrm{N}$-model $\left(\mathbf{N}-\mathbf{T S}_{\mathbf{1 2 - 1 6}}\right)$ reveal that the catalyst would not participate in the cyclization reaction giving high and similar relative free energy values, $\Delta \mathrm{G}^{\#}, 73.5$ and $73.8 \mathrm{Kcal} \mathrm{mol}^{-1}$ respectively. However, based on our experimental results the reaction is accelerated in the presence of the investigated catalysts. At this regard, it is important to note that the reaction in absence of any catalyst gives $50 \%$ of conversion with $36 \%$ of selectivity to 1 after $4 \mathrm{~h}$ of reaction time. Therefore, considering the formation of intermediate compounds $\mathbf{1 2}$ and $\mathbf{1 3}$ we could assume that the preferred operative pathways for the formation of quinoxaline 1 could be the path $\mathbf{b}$ or $\mathbf{c}$ (Scheme 4).

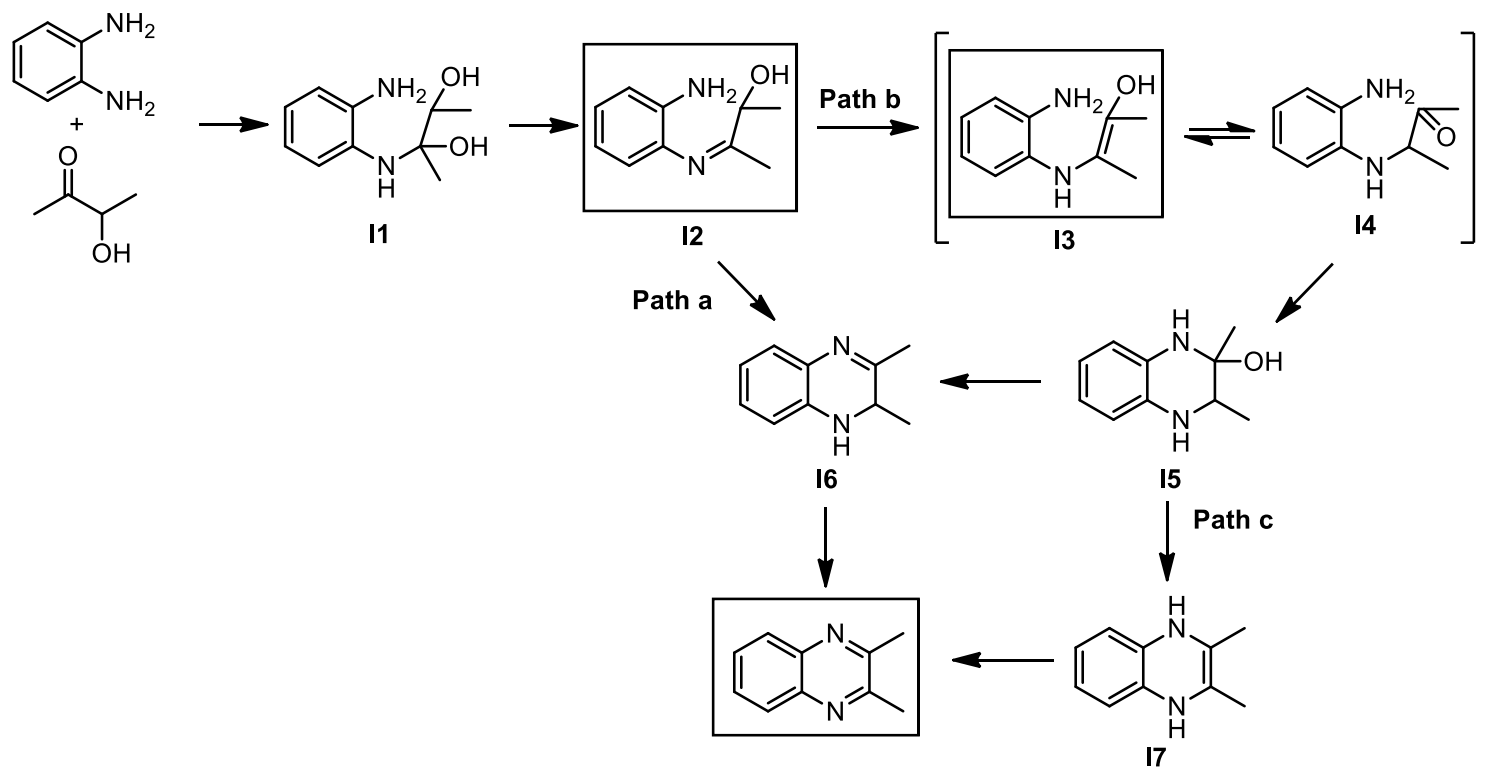

Scheme 4. Alternative reaction route for the synthesis of quinoxaline 1 from $o$ phenylendiamine $\mathbf{2}$ and $\alpha$-hydroxi ketones.

Figure 8 depicts both pathways for the four systems, uncatalyzed and the models selected for simulating the active centers of the investigated carbon catalysts. 

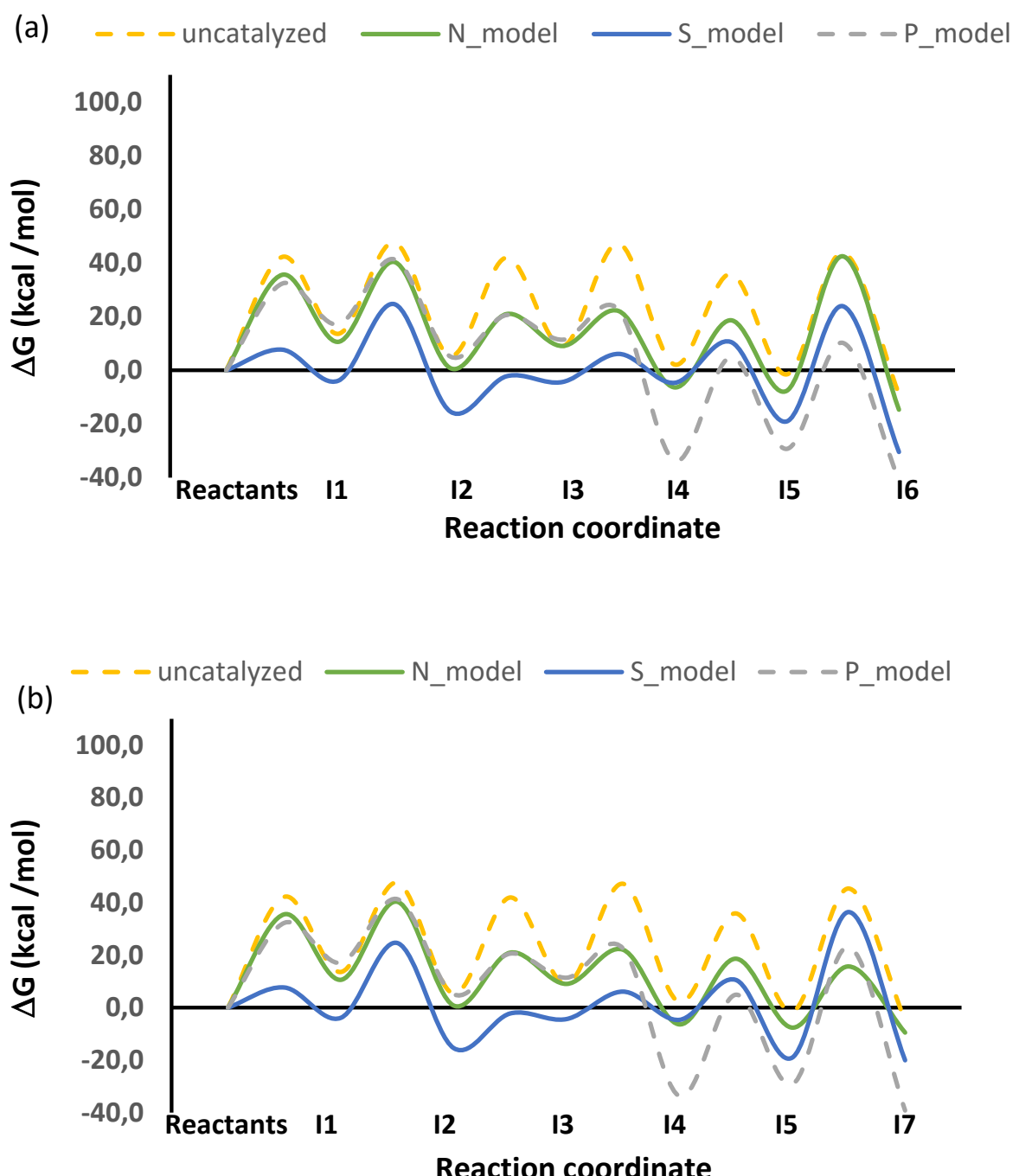

Figure 8. Free-energy profiles computed for the uncatalyzed, N, S and P-models catalytic systems following (a) path $b$ and (b) path $c$ in the formation of quinoxaline 1.

Both pathways for the uncatalyzed reaction show that the relative free-energy values for all the computed transition structures are the highest for each elementary step (close to $40 \mathrm{kcal} \mathrm{mol}^{-1}$ ) more than those found for the catalyzed processes. Two interesting finding were found for the uncatalyzed reaction: (1) initial reactant complex is formed, in which both reagents interact by intra- and intermolecular $\mathrm{H}$-bonds, favoring the approaching of the reagents, and (2) the involvement of one water molecule in $\mathbf{T S}_{\mathbf{1 1 - 1 2}}, \mathbf{T S}_{\mathbf{1 2 - 1 3}}$ and $\mathbf{T S _ { 1 3 - 1 4 }}$ notably decreasing the activation barrier (from 46.1 to $13.0 \mathrm{kcal}^{\mathrm{mol}} \mathbf{l}^{-1}$ for $\mathbf{T S}_{11-12}$ and $\mathbf{T S} \mathbf{S}_{1-12 \mathrm{w}}$, respectively). This fact has been previously observed by the authors in dehydration and heterocyclization reactions since water 
molecules can act as bifunctional acid-base catalyst $[40,41]$. In the same context, the reactant complex formation is also observed for the catalyzed processes in which the acidic proton of the catalysts is $\mathrm{H}$-bounded to the carbonyl acceptor and to the adjacent amine function.

In Figure 9 is shown the optimized transition states $\mathbf{T S}_{\mathbf{1 1}}$ for the first step of the reaction, comprising the nucleophilic attack of an amine group from $\mathbf{2}$ to acetoin for the four investigated systems. In all the cases it was observed the formation of $\mathrm{C}-\mathrm{N}$ bond $(1.72287-1.57017 \AA)$, simultaneously initiating the hydrogen migration from $\mathrm{N} 2$ to $\mathrm{N} 4$ in which the $-\mathrm{O}-\mathrm{H}$ groups from the catalytic model is also involved, thus assisting the almost formation of alcohol in I1. It is clear that the acidity plays an important role in the first step of the reaction since the most acid model shows the most advanced TS.

(a)

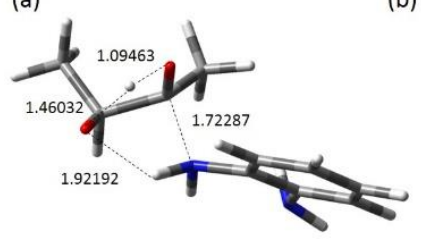

(c)

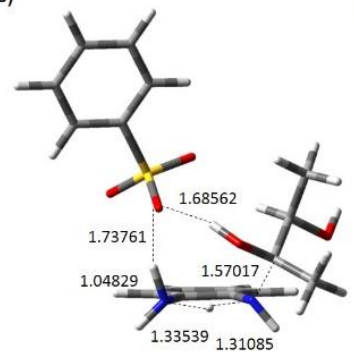

(b)
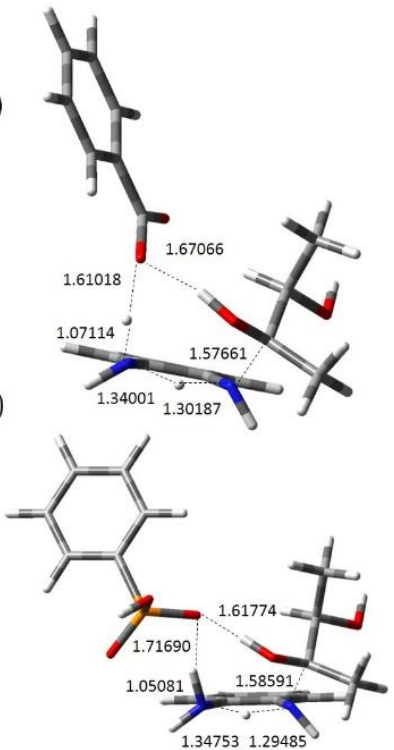

Figure 9. Optimized transition structures for the nucleophilic attack of 2 to acetoin. (a) $\mathbf{T S}_{\mathrm{R}-1 \mathbf{1}}$ in the absence of any catalyst (b) N-model; (c) S-models and (d) P-model. Relevant distances are expressed in $\AA$.

Comparing the energy profiles shown in the Figure 8 , it is observed reduced free-energy values (6.6-9.9 kcal mol${ }^{-1}$ for $\mathbf{T S}_{\mathrm{R}-11}$ and 6.3-7.3 $\mathrm{kcal} \mathrm{mol}^{-1}$ for $\left.\mathbf{T S}_{\mathbf{1 1 - 1 2 \mathrm { w }}}\right)$ for the initial nucleophilic additions and dehydrations in the presence of $\mathrm{N}$ and $\mathrm{P}$-models, this decrease being more pronounced in 
the case of S-model probably due to the higher acidity of the sulfonic acid functions as expected. It is important to note that the intermediate $\mathbf{1 3}$ was not experimentally observed when the reaction was carried out when using acetoin instead benzoin probably due to the additional stabilization by the presence of phenyl groups. The main energy differences were observed for the following elementary steps comprising successive imine-enamine and enol-keto tautomerisms followed by heterocyclization to give $\mathbf{1 5}$ in which the energy barrier is notable decreased in the presence of acid catalytic models (Figure 8). Barely energetic differences exist for the dehydration of $\mathbf{1 5}$ to $\mathbf{1 6}$ or $\mathbf{1 7}$ for the uncatalyzed process. However, the obtained results suggest that this feature is changed for the catalytic processes; while the reaction in the presence of $\mathrm{N}$-model seems to occur following the path $\mathrm{c}, \mathrm{S}$ - and P-models would catalyze the reaction though the path $\mathbf{b}$. At this respect, traces of intermediate compound $\mathbf{1 7}$ were exclusively detected in the ${ }^{1} \mathrm{H}$ NMR spectra for the reaction catalyzed by XN ( $\mathrm{N}$-model), by the presence of signal centered at $\delta 6.5$ which could be assigned to the aromatic protons of the dyhidroquinoxaline skeleton.

Finally, both intermediate compounds $\mathbf{1 6}$ or $\mathbf{1 7}$ could evolve to quinoxaline $\mathbf{1}$ by oxidative aromatization in the presence of acid carbon catalysts under study. This fact is supported by studies concerning the oxidative conversion of a great variety of compounds such as benzylic and allylic alcohols and different nitrogen heterocycles including 2-arylimidazolines, indolines, pyrazolines, 3,4-dihydropyrimidin-2(1H)-ones, among others, by using activated carbonmolecular oxygen systems [42]. It seems that the surface area, the micro- and mesoporosity and the amount of the oxygenated functional groups and the type of acid sites can play an important role in the oxidative reaction.

\section{Conclusions}

We report herein for the first-time acid biomass-derived carbons able to efficiently catalyze the synthesis of quinoxalines. Using the biomass Hedychium gardnerianum, an undesired invasive 
plant, as precursor it was possible to obtain ACs with highly developed porosity by chemical activation with $\mathrm{H}_{3} \mathrm{PO}_{4}$. The obtained carbon material (RCB2) presented very promising textural properties with a BET area of $2197 \mathrm{~m}^{2} \mathrm{~g}^{-1}$ and a pore volume of $1.39 \mathrm{~cm}^{3} \mathrm{~g}^{-1}$, comprising both micro and mesopores. The chemical activation step allowed the simultaneous activation and functionalization of the carbon surface, with the introduction of phosphorus base functional groups. These biomass derived carbons revealed high activity and selectivity in the synthesis of quinoxaline 1 from o-phenylendiamine 2 and benzoin 3, 94\% conversion and 83\% selectivity. Our experimental and theoretical results demonstrate that the reaction is mainly controlled by the type and number of acid sites following an alternative reaction pathway consisting of: (1) nucleophilic addition between reactants and subsequent dehydration, (2) successive imineenamine and ceto-enol tautomerisms, (3) heterocyclization followed by dehydration, and finally (4) aromatization to give quinoxalines, but also the micro-and mesoporosity could be also involved in the last oxidative reaction.

\section{Acknowledgements}

This work has been supported by Spanish Ministry (CTM 2014-56668-R project) and Associated Laboratory for Sustainable Chemistry - Clean Processes and Technologies - LAQV which is financed by national funds from FCT/MEC (UID/QUI/50006/2013) and co-financed by the ERDF under the PT2020 Partnership Agreement (POCI-01-0145-FEDER - 007265). Ines Matos thanks FCT for the Investigador FCT contract IF/01242/2014/CP1224/CT0008 and M. Bernardo for postdoc fellowship (SFRH/BPD/93407/2013). Authors also thank to Dr. Helena Cristina Meneses e Vasconcelos from Universidade dos Açores, for the vegetal precursor. I, Matos also thanks Fundacion Carolina.

\section{References}

[1] C.R. Correa, A. Kruse, Biobased functional carbon materials: Production, characterization, and applications-A review, Materials (Basel). 11 (2018) 1568. doi:10.3390/ma11091568. 
[2] N. Supanchaiyamat, K. Jetsrisuparb, J.T.N. Knijnenburg, D.C.W. Tsang, A.J. Hunt, Lignin materials for adsorption: Current trend, perspectives and opportunities, Bioresour. Technol. 272 (2019) 570-581. doi:10.1016/J.BIORTECH.2018.09.139.

[3] K. Gawl, Z. Status, R. Assessment, R. Last, R. Florestais, Hedychium gardnerianum (kahili ginger), Invasoras.Pt. (2014) 4-7.

[4] F. Rodŕíguez-Reinoso, A. Seṕulveda-Escribano, Carbon Materials for Catalysis, in: Carbon Mater. Catal., John Wiley \& Sons, 2008: pp. 131-155. doi:10.1002/9780470403709.ch4.

[5] I. Matos, M. Bernardo, I. Fonseca, Porous carbon: A versatile material for catalysis, Catal. Today. 285 (2017) 194-203. doi:10.1016/j.cattod.2017.01.039.

[6] E. Pérez-Mayoral, V. Calvino-Casilda, E. Soriano, Metal-supported carbon-based materials: opportunities and challenges in the synthesis of valuable products, Catal. Sci. Technol. 6 (2016) 1265-1291. doi:10.1039/C5CY01437A.

[7] S. De, A.M. Balu, J.C. Van Der Waal, R. Luque, Biomass-derived porous carbon materials: Synthesis and catalytic applications, ChemCatChem. 7 (2015) 1608-1629. doi:10.1002/cctc.201500081.

[8] R.M. P Pérez-Mayoral, E.; Calvino-Casilda, V.; Godino, M.; López-Peinado, A. J.; MartínAranda, Green Synthetic Approaches for Biologically Relevant Heterocycles: An Overview, in: G. Brahmachari (Ed.), Green Synth. Approaches Biol. Relev. Heterocycles, Elsevier Science, 2015: pp. 378-403. doi:10.1016/B978-0-12-800070-0.00011-6.

[9] E. Pérez-Mayoral, E. Soriano, F.J. Martín-Aranda, R. M. Maldonado-Hódar, Mesoporous Catalytic Materials and Fine Chemistry., in: M. Aliofkhazrae (Ed.), Compr. Guid. Mesoporous Mater. Vol. 1 Synth. Charact., Nova Science Publishers, Inc., 2015: pp. 83118.

[10] J.A. Pereira, A.M. Pessoa, M.N.D.S. Cordeiro, R. Fernandes, C. Prudêncio, J.P. Noronha, 
M. Vieira, Quinoxaline, its derivatives and applications: A State of the Art review, Eur. J. Med. Chem. 97 (2015) 664-672. doi:10.1016/j.ejmech.2014.06.058.

[11] K.T. Venkateswara Rao, P.S. Sai Prasad, N. Lingaiah, Iron exchanged molybdophosphoric acid as an efficient heterogeneous catalyst for the synthesis of quinoxalines, J. Mol. Catal. A Chem. 312 (2009) 65-69. doi:10.1016/j.molcata.2009.07.005.

[12] T. Huang, D. Jiang, J. Chen, W. Gao, J. Ding, H. Wu, Silica sulfuric acid (SSA)/polyethylene glycol (PEG) as a recyclable system for the synthesis of quinoxalines and pyrazines, Synth. Commun. 41 (2011) 3334-3343. doi:10.1080/00397911.2010.517894.

[13] B. Das, K. Venkateswarlu, K. Suneel, A. Majhi, An efficient and convenient protocol for the synthesis of quinoxalines and dihydropyrazines via cyclization-oxidation processes using $\mathrm{HClO} 4 \cdot \mathrm{SiO} 2$ as a heterogeneous recyclable catalyst, Tetrahedron Lett. 48 (2007) 5371-5374. doi:10.1016/j.tetlet.2007.06.036.

[14] V. Jeena, R.S. Robinson, An environmentally friendly, cost effective synthesis of quinoxalines: The influence of microwave reaction conditions, Tetrahedron Lett. 55 (2014) 642-645. doi:10.1016/j.tetlet.2013.11.100.

[15] L.Y. Fan, L. Wei, W.J. Hua, X.X. Li, Yb modified NaY zeolite: A recyclable and efficient catalyst for quinoxaline synthesis, Chinese Chem. Lett. 25 (2014) 1203-1206. doi:10.1016/j.cclet.2014.03.003.

[16] G.H. Dang, Y.T.H. Vu, Q.A. Dong, D.T. Le, T. Truong, N.T.S. Phan, Quinoxaline synthesis via oxidative cyclization reaction using metal-organic framework $\mathrm{Cu}(\mathrm{BDC})$ as an efficient heterogeneous catalyst, Appl. Catal. A Gen. 491 (2015) 189-195. doi:10.1016/j.apcata.2014.11.009.

[17] V.K. Akkilagunta, V.P. Reddy, R.R. Kakulapati, Aqueous-phase aerobic oxidation of alcohols by $\mathrm{Ru} / \mathrm{C}$ in the presence of cyclodextrin: One-pot biomimetic approach to 
quinoxaline synthesis, Synlett. 2010 (2010) 2571-2574. doi:10.1055/s-0030-1258775.

[18] N. Shah, E. Gravel, D. V. Jawale, E. Doris, I.N.N. Namboothiri, Synthesis of quinoxalines by a carbon nanotube-gold nanohybrid-catalyzed cascade reaction of vicinal diols and keto alcohols with diamines, ChemCatChem. 7 (2015) 57-61. doi:10.1002/cctc.201402782.

[19] M. Godino-Ojer, E. Soriano, V. Calvino-Casilda, F.J. Maldonado-Hódar, E. Pérez-Mayoral, Metal-free synthesis of quinolines catalyzed by carbon aerogels: Influence of the porous texture and surface chemistry, Chem. Eng. J. 314 (2017) 488-497. doi:10.1016/j.cej.2016.12.006.

[20] J. Lõpez-Sanz, E. Pérez-Mayoral, E. Soriano, D. Omenat-Morán, C.J. Durán, R.M. MartínAranda, I. Matos, I. Fonseca, Acid-activated carbon materials: Cheaper alternative catalysts for the synthesis of substituted quinolines, ChemCatChem. 5 (2013) 3736-3742. doi:10.1002/cctc.201300626.

[21] I. Matos, P.D. Neves, J.E. Castanheiro, E. Perez-Mayoral, R. Martin-Aranda, C. DuranValle, J. Vital, A.M. Botelho Do Rego, I.M. Fonseca, Mesoporous carbon as an efficient catalyst for alcoholysis and aminolysis of epoxides, Appl. Catal. A Gen. 439-440 (2012) 24-30. doi:10.1016/j.apcata.2012.06.036.

[22] Y. Zhai, Y. Dou, X. Liu, S.S. Park, C.S. Ha, D. Zhao, Soft-template synthesis of ordered mesoporous carbon/nanoparticle nickel composites with a high surface area, Carbon N. Y. 49 (2011) 545-555. doi:10.1016/j.carbon.2010.09.055.

[23] Y. Meng, D. Gu, F. Zhang, Y. Shi, L. Cheng, D. Feng, Z. Wu, Z. Chen, Y. Wan, A. Stein, D. Zhao, A family of highly ordered mesoporous polymer resin and carbon structures from organic-organic self-assembly, Chem. Mater. 18 (2006) 4447-4464. doi:10.1021/cm060921u.

[24] Y. Meng, D. Gu, F. Zhang, Y. Shi, H. Yang, Z. Li, C. Yu, B. Tu, D. Zhao, Ordered mesoporous 
polymers and homologous carbon frameworks: Amphiphilic surfactant templating and direct transformation, Angew. Chemie - Int. Ed. 44 (2005) 7053-7059. doi:10.1002/anie.200501561.

[25] C. Lin, J.A. Ritter, Effect of synthesis PH on the structure of carbon xerogels, Carbon N. Y. 35 (1997) 1271-1278. doi:10.1016/S0008-6223(97)00069-9.

[26] J.S. Noh, J.A. Schwarz, Estimation of the point of zero charge of simple oxides by mass titration, J. Colloid Interface Sci. 130 (1989) 157-164. doi:10.1016/0021-9797(89)900866.

[27] F. Mohsenzadeh, K. Aghapoor, H.R. Darabi, Benign approaches for the microwaveassisted synthesis of quinoxalines, J. Braz. Chem. Soc. 18 (2007) 297-303. doi:10.1590/S0103-50532007000200009.

[28] D.J.F. M.J. Frisch, G.W. Trucks, H.B. Schlegel, G.E. Scuseria, M.A. Robb, J.R. Cheeseman, G. Scalmani, V. Barone, B. Mennucci, G.A. Petersson, H. Nakatsuji, M. Caricato, X. Li, H.P. Hratchian, A.F. Izmaylov, J. Bloino, G. Zheng, J.L. Sonnenberg, M.Hada, M. Ehara, Gaussian 09 Revision B.01, Gaussian,Inc., Wallingford CT, 2010, (n.d.).

[29] M. Thommes, K. Kaneko, A. V Neimark, J.P. Olivier, F. Rodriguez-reinoso, J. Rouquerol, K.S.W. Sing, Physisorption of gases, with special reference to the evaluation of surface area and pore size distribution ( IUPAC Technical Report ), Pure Appl. Chem. 87 (2015) 1051-1069. doi:10.1515/pac-2014-1117.

[30] Y. Meng, D. Gu, F. Zhang, Y. Shi, H. Yang, Z. Li, C. Yu, B. Tu, D. Zhao, Ordered mesoporous polymers and homologous carbon frameworks: Amphiphilic surfactant templating and direct transformation, Angew. Chemie - Int. Ed. 44 (2005) 7053-7059. doi:10.1002/anie.200501561.

[31] S.M. Yakout, G. Sharaf El-Deen, Characterization of activated carbon prepared by 
phosphoric acid activation of olive stones, Arab. J. Chem. 9 (2016) S1155-S1162. doi:10.1016/J.ARABJC.2011.12.002.

[32] G.Z. Zhu, X.L. Deng, M. Hou, K. Sun, Y.P. Zhang, P. Li, F.M. Liang, Comparative study on characterization and adsorption properties of activated carbons by phosphoric acid activation from corncob and its acid and alkaline hydrolysis residues, Fuel Process. Technol. 144 (2016) 255-261. doi:10.1016/j.fuproc.2016.01.007.

[33] J.S. Duke-Cohan, C. Morimoto, S.F. Schlossman, Depletion of the helper/inducer (memory) T cell subset using a bispecific antibody-toxin conjugate directed against CD4 and CD29, Transplantation. 56 (1993) 1188-1196. doi:10.1002/aic.12056.

[34] I. Matos, M.F. Silva, R. Ruiz-Rosas, J. Vital, J. Rodríguez-Mirasol, T. Cordero, J.E. Castanheiro, I.M. Fonseca, Methoxylation of a-pinene over mesoporous carbons and microporous carbons: A comparative study, Microporous Mesoporous Mater. 199 (2014) 66-73. doi:10.1016/j.micromeso.2014.08.006.

[35] C.J. Durán-Valle, M. Madrigal-Martínez, M. Martínez-Gallego, I.M. Fonseca, I. Matos, A.M. Botelho Do Rego, Activated carbon as a catalyst for the synthesis of $\mathrm{N}$ alkylimidazoles and imidazolium ionic liquids, Catal. Today. 187 (2012) 108-114. doi:10.1016/j.cattod.2011.12.021.

[36] A.F. Carvalho, A.J.S. Fernandes, C. Leitão, J. Deuermeier, A.C. Marques, R. Martins, E. Fortunato, F.M. Costa, Laser-Induced Graphene Strain Sensors Produced by Ultraviolet Irradiation of Polyimide, Adv. Funct. Mater. $28 \quad$ (2018) 1805271. doi:10.1002/adfm.201805271.

[37] B.P. Payne, M.C. Biesinger, N.S. McIntyre, X-ray photoelectron spectroscopy studies of reactions on chromium metal and chromium oxide surfaces, J. Electron Spectros. Relat. Phenomena. 184 (2011) 29-37. doi:10.1016/j.elspec.2010.12.001. 
[38] H.K. Kadam, S. Khan, R.A. Kunkalkar, S.G. Tilve, Graphite catalyzed green synthesis of quinoxalines, Tetrahedron Lett. 54 (2013) 1003-1007. doi:10.1016/j.tetlet.2012.12.041.

[39] M.R. Islami, Z. Hassani, One-pot and efficient protocol for synthesis of quinoxaline derivatives, Arkivoc. 2008 (2008) 280-287. doi:10.3998/ark.5550190.0009.f24.

[40] A. Smuszkiewicz, J. López-Sanz, E. Pérez-Mayoral, E. Soriano, I. Sobczak, M. Ziolek, R.M. Martín-Aranda, A.J. López-Peinado, Amino-grafted mesoporous materials based on MCF structure involved in the quinoline synthesis. Mechanistic insights, J. Mol. Catal. A Chem. 378 (2013) 38-46. doi:10.1016/j.molcata.2013.05.017.

[41] M. Godino-Ojer, A.J. Lõpez-Peinado, R.M. Martín-Aranda, J. Przepiõrski, E. PérezMayoral, E. Soriano, Eco-friendly catalytic systems based on carbon-supported magnesium oxide materials for the friedländer condensation, ChemCatChem. 6 (2014) 3440-3447. doi:10.1002/cctc.201402602.

[42] M. Hayashi, Oxidation using activated carbon and molecular oxygen system, Chem. Rec. 8 (2008) 252-267. doi:10.1002/tcr.20152. 